\title{
Dielectric Characteristics of Spin-coated Dielectric Films Using On-wafer Parallel-plate Capacitors at Microwave Frequencies
}

\author{
A. N. AL-Omari and K. L. Lear \\ Electrical and Computer Engineering Department \\ Colorado State University, Fort Collins, CO 80523-1373, USA
}

\begin{abstract}
Dielectric properties of spin-coated dielectric insulators suitable for high-speed device fabrication are investigated. Complex dielectric permittivities and tangential losses of two polyimides, bisbenzocyclobutene (BCB), and a spin-on-glass (SOG) were extracted from the measured microwave reflection coefficient, $S_{11}$, of parallel-plate capacitors over a frequency range of $50 \mathrm{MHz}$ to $40 \mathrm{GHz}$. A model for the dielectric permittivity as a function of frequency is developed based on measured data with a minimum square error of less than $10^{-4}$ between measured and modeled microwave reflection coefficients. A circuit model for the pad capacitance is obtained based on geometrical and physical considerations. The relationship between the dielectric loss and its thickness is considered. Experimental results are fitted to Debye and Cole-Cole models.
\end{abstract}

Index Terms - Dielectric permittivity, dielectric loss, tangential loss, polymer films, polyimide, bisbenzcyclobutene (BCB), spin-on glass (SOG), Debye model, Cole-Cole model, pad capacitance.

\section{INTRODUCTION}

A $\mathrm{S}$ devices become smaller, faster and more powerful, the demands on both materials and processes used by the manufacturers of microelectronic devices become more critical. Dielectrics play a significant role in achieving the current state-of-the art in microelectronics [1-3]. They are typically applied in semiconductor micro-fabrication for a number of applications such as stress buffers to accommodate built-in strains as well as strain induced by forced bending $[4,5]$, surface planarization and passivation [6], dielectric isolation layers [7,8], die bonding [9], and buried channel waveguides [10].

Spin-on dielectrics are used in fabricating many high speed electronic devices for reduction of parasitic circuit elements that may limit device speed. In heterojunction bipolar transistors (HBTs), parasitics were reduced by collector implantation [11] or by double polymer planarization [12]. A multilayer polymer structure was used to reduce parasitic capacitance of permeable base transistors (PBTs, i.e. vertical MESFETs) [13]. In vertical-cavity surface emitting lasers (VCSELs), polymer was used for planarization, passivation and metal pad parasitic capacitance reduction [14]. Spin-on glass (SOG) has been ac-

Manuscript received on 6 July 2004, in final form 14 April 2005. tively investigated [15-17] for similar applications and has been used in multilevel metal interconnect processes $[15$, $16]$.

When a dielectric material is subjected to an electric field, the bound positive and negative charge constituents are displaced from their average equilibrium positions by the Lorentz electric field forces. The charge adjustment results in several polarization mechanisms including dipolar polarization, ionic polarization, and electronic polarization [18]. Dipolar or orientational polarization occurs when permanent dipoles in asymmetric molecules respond to the applied electric field. Ionic polarization arises when adjacent positive and negative ions are displaced in the presence of an applied electric field. Electronic polarization occurs in neutral atoms when an electric field displaces the negative electron cloud with respect to the positive nucleus. Each polarization mechanism has an associated response time and therefore will not contribute to the dielectric constant beyond some corresponding frequency [19]. The maximum effective response frequency of dipolar, ionic, and electronic mechanisms are on the order of $10^{10} \mathrm{~Hz}, 10^{12} \mathrm{~Hz}$ and $10^{15} \mathrm{~Hz}$, respectively [19].

In this work, dielectric properties of four different spinon dielectrics (Table 1) which are typical options for planarization in the applications mentioned above are inves- 
Table 1. Families, specific verities and general properties of the investigated dielectrics.

\begin{tabular}{|c|c|c|c|c|}
\hline Specific variety & HD-8000 & PI-2723 & BCB-4024 & SOG IC1-200 \\
\hline Manufacturer & HD Microsystems ${ }^{\mathrm{TM}}$ & HD Microsystems $^{\mathrm{TM}}$ & Dow Chemical Cyclotene $\mathrm{T}^{\mathrm{TM}}$ & Futurrex, Inc. \\
\hline Dielectric material & Organic polymer & Organic polymer & Organic polymer & Spin On Glass \\
\hline Family & Polyimide & Polyimide & Bisbenzo- cyclobutene & Polysiloxane \\
\hline Tone & positive & negative & negative & non-photosensitive \\
\hline Cured film thickness $(\mu \mathrm{m})$ & $5-11$ & $1.8-8.5$ & $3.5-7.5$ & $0.5^{\mathrm{a}}$ \\
\hline $\mathrm{Tg}^{\mathrm{b}}\left({ }^{\circ} \mathrm{C}\right)$ & 300 & $>320$ & $>350$ & - \\
\hline $\mathrm{CTE}^{\mathrm{c}}\left(\mathrm{ppm} /\left({ }^{\circ} \mathrm{C}\right)\right.$ & 47 & 57 & 52 & - \\
\hline Elongation (\%) & 11 & 12 & 8 & - \\
\hline Breakdown field (V/cm) & - & $>2 \times 10^{4}$ & $3 \times 10^{6}$ & $3 \times 10^{6}$ \\
\hline Volume resistivity $(\Omega-\mathrm{cm})$ & - & $>10^{16}$ & $10^{19}$ & $5 \times 10^{13}$ \\
\hline Tensile modulus (Gpa) & 2.5 & 2.7 & 2.9 & - \\
\hline Tensile strength (Mpa) & 122 & 160 & 87 & 20 \\
\hline
\end{tabular}

a: Achieved by double spin coating.

b: Glass Transition Temperature.

c: Coefficient of Thermal Expansion.

tigated using the capacitance of high speed VCSEL metal pads as a test geometry for the samples. The development of an accurate equivalent circuit for VCSELs as well as other devices motivates the measurement of complex dielectric permittivities and tangential losses for polyimide, bisbenzocyclobutene, and spin-on-glass dielectrics up to 40GHz. The resulting circuit models are useful for the analysis of bandwidth limitations of laser diodes and other high speed electronic devices as well as matching driver circuits to device impedances.

\section{FABRICATION}

In high speed VCSEL fabrication, dielectrics are used to planarize etched mesas before depositing metal interconnects and bonding pads [14]. A smooth surface is needed for metal interconnect and metal bonding pad lithography and deposition. Polymer coatings also protect the sidewalls of the mesa from the external environment, and it creates an isolation layer between $n$ and $p$ contacts. Although the thermal conductivity of most polymers is poor, it is better than the thermal conductivity of gases in hermetic packages or air. The dielectric properties of the materials used in this work were investigated by fabricating capacitors from the different dielectric materials with various thicknesses and measuring their microwave scattering parameters (S-parameters).

\subsection{FABRICATION OVERVIEW}

Capacitors corresponding to the probe pads of VCSELs were fabricated above conducting ground planes on undoped GaAs substrates as illustrated in Figure 1 which shows a cross-section along AA' of Figure 2. The geometry shown in Figure 2 is nominally that of parallel plates with constant dielectric thickness. While some fringing fields exist, the $80 \mu \mathrm{m}$ width of the central metal pad is much larger than the 0.7 to $7.0 \mu \mathrm{m}$ dielectric thickness listed in Table 2, and there is a relative large minimum separation of $10 \mu \mathrm{m}$ between the central signal and the outside ground pads. Thus the fringing field effects have

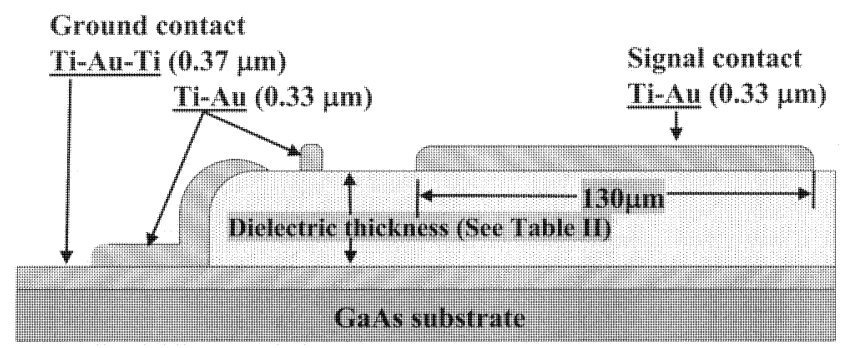

Figure 1. Capacitor cross-section at AA' in Figure 2.

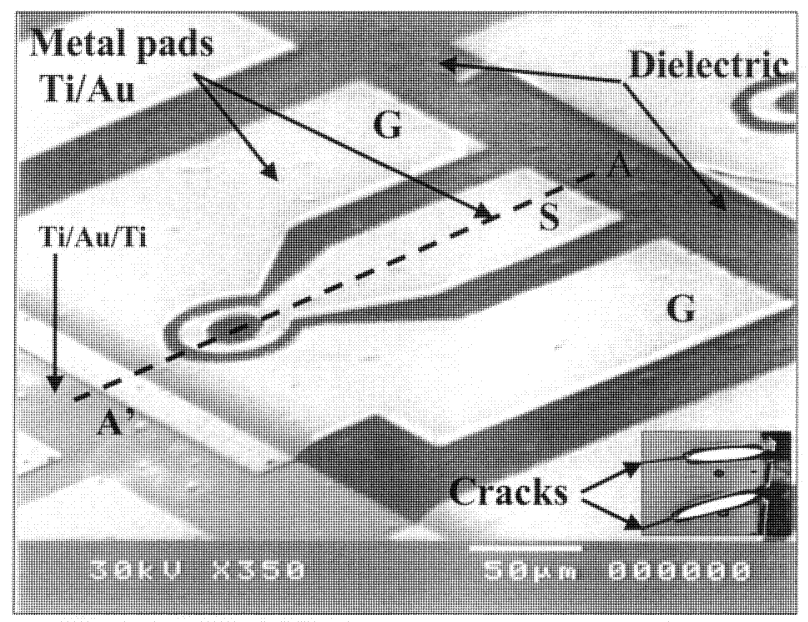

Figure 2. SEM photo for a completed capacitor ready for testing.

been neglected in this study. While a simpler or a larger pad geometry might reduce fringing fields, the triple pad configuration was required for compatibility with coplanar microwave probes, and the annular aperture region was present in the features of the VCSEL photo mask. To form the ground plane, which serves as the lower plate of the capacitor, layers of $\mathrm{Ti}-\mathrm{Au}-\mathrm{Ti}$ with thicknesses of $(100 / 170 / 100) \mathrm{nm}$ were evaporated in sequence on top of the substrate. In addition to serving as the capacitor's bottom plate, these ground plane layers shield the capacitors 
Table 2. Dielectrics fabrication process summary.

\begin{tabular}{lllll}
\hline $\begin{array}{l}\text { Specific } \\
\text { variety }\end{array}$ & $\begin{array}{l}\text { Sample } \\
\text { number }\end{array}$ & $\begin{array}{l}\text { Spin speed } \\
\left(\times 10^{3} \mathrm{rpm}\right)\end{array}$ & $\begin{array}{l}\text { Developing } \\
\text { time }(\mathrm{s})\end{array}$ & $\begin{array}{l}\text { Cured } \\
\text { thickness }(\mu \mathrm{m})\end{array}$ \\
\hline HD-8000 & 1 & 10.0 & 40 & 1.36 \\
& 2 & 5.0 & 55 & 3.6 \\
& 3 & 3.5 & 80 & 5.5 \\
PI-2723 & 4 & 5.5 & 25 & 1.35 \\
& 5 & 2.0 & 30 & 4.1 \\
& 6 & 1.3 & 46 & 6.0 \\
BCB-4024 & 7 & 7.5 & 20 & 1.8 \\
& 8 & 3.5 & 30 & 4.3 \\
& 9 & 2.5 & 55 & 7.2 \\
IC1-200 & 10 & 3.0 & - & 0.65 \\
\hline
\end{tabular}

from the properties of the substrate. The lower layer of $\mathrm{Ti}$ was applied to improve the adhesion of the Au layer to the substrate while the upper Ti layer improves the adhesion of the spin-on dielectric to the lower metal. Au and Ti layers were chosen to be thick enough to withstand the dielectric surface tension and contraction during the curing process. Next, each one of the four different types of dielectrics listed in Table 1 were spun on the ground plane and appropriately patterned and cured. Details of the dielectric fabrication processes will be discussed individually in Section 2.2. Table 1 also shows the general family of the dielectric materials along with their tones, manufacturers, and specific part numbers.

The capacitor's top plate was fabricated with a metal pad mask suitable for on-wafer microwave testing. The co-planar pad configuration was originally designed for use in fabricating VCSELs including an annular contact region as seen in Figure 2. In the present work, the entire pad and annular contact region are insulated from the ground plane by a constant thickness dielectric layer. The pad design greatly reduces inaccuracies in microwave probing associated with parasitic coupling and unwanted mode excitation at the probing tips [20]. A ground-signalground (GSG) contact configuration was chosen as it terminates field lines at the interface effectively and excites the unwanted microstrip modes less than other contact configurations [20, 21].

The metal probe pads and thus capacitor top plates were patterned using the same lift-off process on ten dielectric samples of varying thicknesses of the four materials (Table 2). The photolithography step used AZ4400 photoresist that was soaked in chlorobenzene for five minutes prior to developing to obtain a suitable profile for the liftoff process [22]. Next, the samples were developed using AZ400K developer diluted with DI water (1:4). To reduce the resistance between the ground pads of the top plate and the lower $\mathrm{Ti}-\mathrm{Au}-\mathrm{Ti}$ ground plane, the titanium oxide layer $\mathrm{TiO}_{2}$ that formed on the exposed ground plane during the curing process was wet etched in hydrofluoric acid (HF) diluted with DI water (5\%:95\%) for $\sim 5 \mathrm{~s}$ which is long enough to remove the $\mathrm{TiO}_{2}$ layer and short enough to maintain the dielectric's surface smoothness. Then, Ti$\mathrm{Au}$ was evaporated with thicknesses of $(30 / 300) \mathrm{nm}$ respectively [22]. Figure 2 shows an SEM photo of a completed capacitor structure using the high-speed VCSEL metal interconnect pad design.

\subsection{DIELECTRICS FABRICATION 2.2.1 POLYIMIDES (HD-8000 AND $\mathrm{PI} 2723)$}

Polyimides have been identified as having excellent potential for use in high speed electronic devices, aerospace composites, and air craft wire and cable coating among other applications due to their high inherent thermal stability, and excellent electrical and mechanical properties [23]. One potential disadvantage of polyimides is their moisture absorption [24]. Polyimides are cyclic-chain polymers which are mainly synthesized by a two-step technique. First, polyamic acid is formed by a condensation reaction of a tetracarboxylic acid dianhyride with a dysfunctional base (diamine). Polyamic acid is readily soluble in polar organic solvents. In the second step of the synthesis polyamic acid is cyclodehydrated to the corresponding polyimide by extended heating at an elevated temperature [25], by treating with chemical dehydrating agents [26], or by microwave energy [27]. A typical molecular structure for a photosensitive polyimide after curing is shown in Figure 3a [28].

The dielectric for the first set of capacitors was HD8000 , a photosensitive, positive tone polyimide that can be imaged and processed as a positive tone photoresist. HD8000 capacitors were fabricated as follows. First the standard photolithography process was carried out according

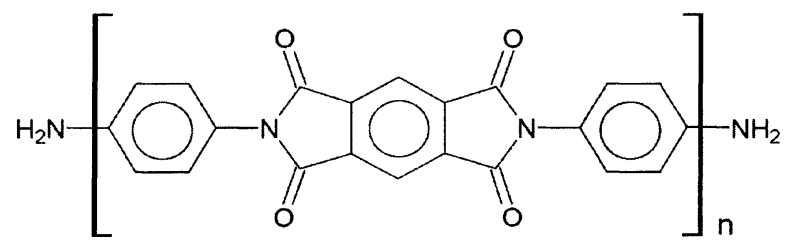

(a)

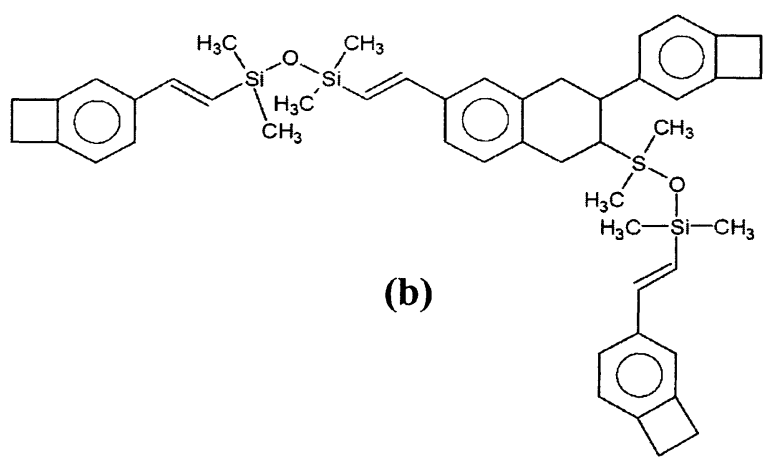

Figure 3. Typical cured molecular structures. a, photosensitive polyimide [28]; b, BCB polymer [32, 33]. 
to the manufacturer's data sheet. To obtain different dielectric thicknesses, different spinning speeds were used for this type of polyimide as well as all other types of dielectrics used in this study. After exposure, the sample was baked for $100 \mathrm{~s}$ at $115^{\circ} \mathrm{C}$. Then, it was left to cool down to ambient temperature for about 30 minutes prior to proceeding with the developing step. Developing polyimide while it is hot leads to severe cracks in the cured polyimide as shown in the inset of Figure 2. Dipping a hot sample in the developer will drop the cured polyimide surface temperature to $20^{\circ} \mathrm{C}$ while the temperature of the polyimide underneath the surface is about $120^{\circ} \mathrm{C}$. As a result the surface of the polyimide contracts more than the polyimide underneath, with the resulting stress cracking the polyimide. The polyimide was developed in the commonly used AZ400K aqueous developer diluted with deionized (DI) water (1:4). After developing, the sample was rinsed by squirting it with DI water while it was spun at 1000 revolution per minute $(\mathrm{rpm})$ for $10 \mathrm{~s}$. Immediately after the rinse, it was spin-dried at $3500 \mathrm{rpm}$ for $10 \mathrm{~s}$. To cure the polyimide the sample was loaded into a curing furnace at $20^{\circ} \mathrm{C}$ in a nitrogen atmosphere, and the temperature was ramped from 20 to $350^{\circ} \mathrm{C}$ over a 60 minute period. The temperature was held at $350^{\circ} \mathrm{C}$ for $30 \mathrm{~min}-$ utes. Finally, the sample was allowed to cool down. The spinning speeds, developing times, and measured HD-8000 polyimide thicknesses after curing are listed in Table 2.

Pyralin ${ }^{\circledR}$ PI-2723 polyimide is a photosensitive negative tone organic polymer which was used to fabricate the second set of capacitors. After the photolithographic exposure, the polyimide was developed using DE-6018 solvent, then further developed in DE-6018 diluted with RI-9045 solvent (1:1), and finally rinsed using RI-9045. To cure the polyimide, the sample was loaded into furnace at $20^{\circ} \mathrm{C}$, and the temperature was ramped from 20 to $150^{\circ} \mathrm{C}$ at about $6.5^{\circ} \mathrm{C} /$ minute. Then the temperature was ramped from 150 to $300^{\circ} \mathrm{C}$ over a 60 minute period. The temperature was held at $300^{\circ} \mathrm{C}$ for 30 minutes. Table 2 lists the cured thicknesses of the PI-2723 polyimide as well as other process parameters.

\subsubsection{BISBENZOCYCLOBUTENE (BCB-4024)}

Bisbenzocyclobutene (BCB) has been traditionally used as a polymer dielectric for many multichip module (MCM) applications [29]. The thermal curing of Cyclotene ${ }^{\mathrm{TM}}$ polymers is a two-step process. First the benzocyclobutene ring opens thermally to produce an o-quinodimethane intermediate. Next, the o-quinodimethane undergoes a Diels-Alder reaction with residual alkene groups in the prepolymer, forming a tri-substituted tetrahydronaphthalene [30]. One difference with respect to polyimide is that $\mathrm{BCB}$ does not evolve water during crosslinking. After curing, the crosslinked $\mathrm{BCB}$ polymer has low moisture uptake. The main disadvantage of $\mathrm{BCB}$ is the thermal stabil- ity of the cured film [31]. Figure $3 b$ shows standard cured photosensitive $\mathrm{BCB}$ polymer structure [32, 33].

BCB-4024 is a photosensitive, negative-tone polymer that was used for the third set of capacitors. Following the photolithographic exposure process, the polymer was developed using the DS-2100 solvent. To cure the polymer the sample was loaded into a furnace and the temperature was ramped from 20 to $150^{\circ} \mathrm{C}$ at $4.5^{\circ} \mathrm{C} /$ minute. The temperature was held at $150^{\circ} \mathrm{C}$ for 15 minutes. Then, the temperature was ramped from 150 to $250^{\circ} \mathrm{C}$ over a 10 minute period. The temperature was held at $250^{\circ} \mathrm{C}$ for 40 minutes. The measured BCB-4024 polymer thicknesses after curing are shown in Table 2 along with the corresponding developing times and spinning speeds.

\subsubsection{SPIN-ON GLASS (IC1-200)}

Intermediate coating IC1-200 is a high transparency polysiloxane-based spin-on dielectric material, which contains methyl and unspecified alkoxy groups bounded to silicon atoms with carbon contents in the range of $20-30 \%$ [34]. IC1-200 is used primarily in the planarization of topography on integrated circuits in multilevel metal techniques. SOG is applied as a dielectric in a permanent or a partial etchback mode. It can be utilized as an intermediate layer in the trilayer resist technique and as a protective layer for plastics and metals [34].

IC1-200 was spun at $3000 \mathrm{rpm}$ for $30 \mathrm{~s}$. Then it was baked on a hot plate at $100^{\circ} \mathrm{C}$ for one minute and at $200^{\circ} \mathrm{C}$ for another one minute. Next, a second layer of SOG was spun and baked at same temperatures used for the first layer. After that, positive tone photoresist was patterned and developed to serve as a mask covering a part of the SOG area. The exposed SOG was etched using an reactive ion etching (RIE) system for ten minutes with chlorine and oxygen (2:1) at approximately $100 \mathrm{~mW}$ power and $20 \mathrm{~Pa}$ (150 mTorr) pressure. Then the photoresist was striped and the SOG was cured at $400^{\circ} \mathrm{C}$ for 30 minutes in a nitrogen gas flow that prevents the SOG from oxidation, which can cause flakes to form. After curing the SOG has an approximate thickness of $\sim 0.65 \mu \mathrm{m}$. Only this single thickness was used to fabricate SOG capacitors. The vendor recommended a maximum film thickness of $\sim 0.5 \mu \mathrm{m}$ as thicker films can have excessive tensile stress that leads to the film cracking. Table 2 summarizes the cured dielectric thicknesses and their corresponding developing times and spinning speeds.

\section{MEASUREMENTS}

The fundamental properties of dielectric materials can be measured either in the frequency domain or in the time domain using suitable transformation techniques to obtain the frequency dependence of the materials properties. One motivation for the development of time domain techniques was the necessity of different frequency domain 
methods and instruments to cover a frequency range of 1 $\mathrm{Hz}$ up to $10 \mathrm{GHz}$ [35]. Frequency domain measurements were used in this study since time-domain techniques assume the system is linear and any unexpected non-linearity introduces complications in the transformation technique to be adapted [35, 36]. Furthermore it is now possible to use a single instrument to cover a wide range of frequencies.

A variety of techniques can be used to measure the properties of dielectric materials in the frequency domain. The auto balancing bridge technique is accurate in the frequency range from a few $\mathrm{Hz}$ to $110 \mathrm{MHz}$. The currentvoltage (IV) and RF-IV techniques are also accurate and can be applied from $40 \mathrm{~Hz}$ to $3 \mathrm{GHz}$. The Transmission/Reflection technique can be utilized for a frequency range from a few $\mathrm{Hz}$ to $110 \mathrm{GHz}$ [37].

Based on the frequency range of the available equipment, the transmission/reflection technique was applied. The $S_{11}$ parameter measurement apparatus consisted of an Agilent 8722ET vector network analyzer (VNA) with $40 \mathrm{GHz}$ bandwidth, a computer with GPIB card to load the calibration kit into the VNA, a high precision Cascade Microtech impedance standard substrate (ISS-101-190), a probe station with a room temperature stage, a fiber optic illuminator to reduce sample temperature variations, a CCD camera, and Cascade Microtech air co-planar probes (ACP40) with a GSG configuration, $125 \mu \mathrm{m}$ pitch, and $\mathrm{Be}-\mathrm{Cu}$ tips which provide repeatable contact on gold pads. The use of ACP with GSG configuration helps deliver the RF signals with minimal attenuation and good impedance control, which results in accurate measurements [38].

The $\mathrm{S}_{11}$ parameter measurements proceeded as follows; isopropyl alcohol diluted with DI water and lint-free wipes were used to clean the mating surfaces so that the measurements are not affected by dirt and impurities. RF cable reflection stability and connector repeatability were verified. The largest drift in the reflection coefficient for the cable terminated with an open circuit was $-57 \mathrm{~dB}$ which corresponds to a 0.0014 change in voltage ampli-

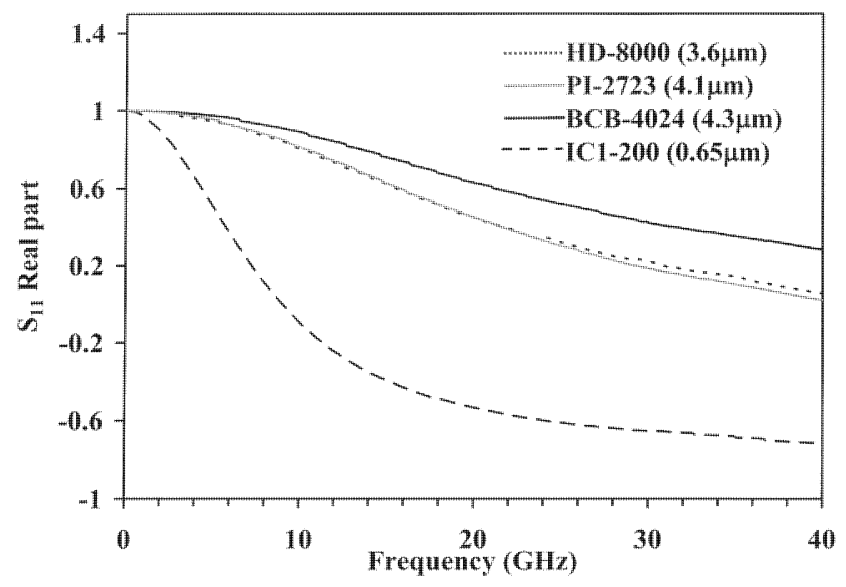

Figure 4. Real part of $S_{11}$ parameter vs. frequency.

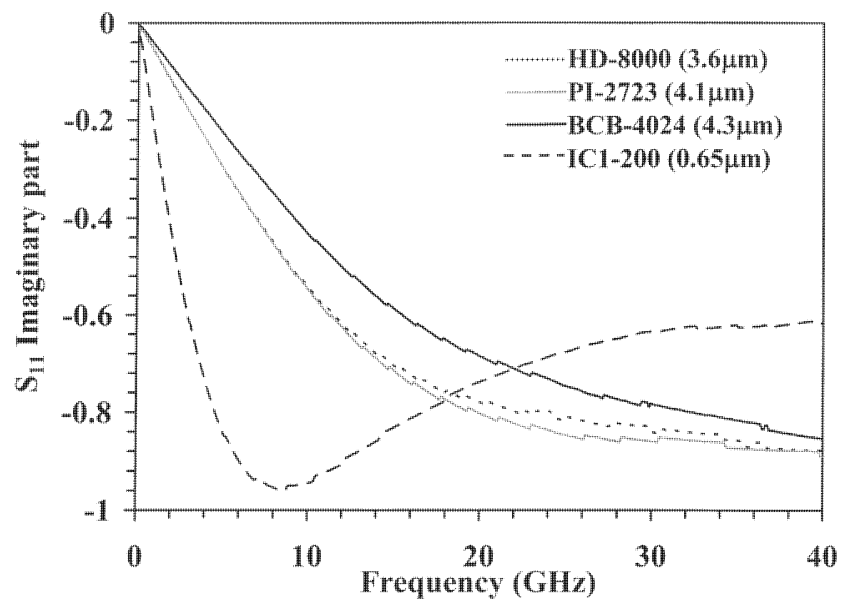

Figure 5. Imaginary part of $S_{11}$ parameter vs. frequency.

tude. The VNA was calibrated at a power level of -10 $\mathrm{dBm}(0.1 \mathrm{~mW})$ in order to maximize signal to noise ratio while not being so large as to require attenuation of the reflected signal. A low IF bandwidth of $100 \mathrm{~Hz}$ was used to reduce noise. The measurement repeatability was improved by operating the VNA in stepped frequency mode, rather than with continuous sweep and by applying the VNA built in averaging and smoothing functions. One-port calibration using a standard short-open-load (SOL) was carried out. Next the capacitor's microwave reflection coefficients were measured over a frequency range of 50 $\mathrm{MHz}$ to $40 \mathrm{GHz}$. Figures 4 and 5 show the real and imaginary parts of the measured reflection coefficients respectively for the dielectrics listed in Table 1 . The raw data exhibited some ripples with magnitudes on the order of $10^{-3}$ that were filtered out using the VNA built-in smoothing and averaging functions. To maintain clarity, only the data for selected dielectric thicknesses are shown.

\section{COMPLEX PERMITTIVITY AND TANGENTIAL LOSS EXTRACTION}

The complex permittivity and tangential loss are regarded as the most important parameters for describing dielectric properties [39]. The relative permittivity can be expressed in the complex form $\varepsilon^{*}=\varepsilon^{\prime}-j \varepsilon^{\prime \prime}$, where $\varepsilon^{\prime}$ is the relative dielectric constant which characterizes a material's ability to store charges, and $\varepsilon^{\prime \prime}$ is the dielectric loss which is a measure of the dissipation in the material. The dielectric loss is typically quantified in terms of a material's dielectric loss tangent, $\tan \left|\delta_{d}\right|=\varepsilon^{\prime \prime} / \varepsilon^{\prime}$, where $\delta_{d}$ is the dielectric loss angle [40, 41].

The impedance of a capacitor with a lossy dielectric is given by $Z=d /\left(j \omega \varepsilon_{0} \varepsilon^{*} A\right)$ [42], where $\varepsilon_{0}$ is the free space permittivity $8.85 \times 10^{-12} \mathrm{~F} / \mathrm{m}, \mathrm{A}$ is the capacitor area which is fixed for all capacitors in this study at 10400 $\mu \mathrm{m}^{2}, d$ is the thickness of the dielectric, and $\omega$ is the angular frequency. The measured impedances of the fabricated capacitors can be calculated from the measured 


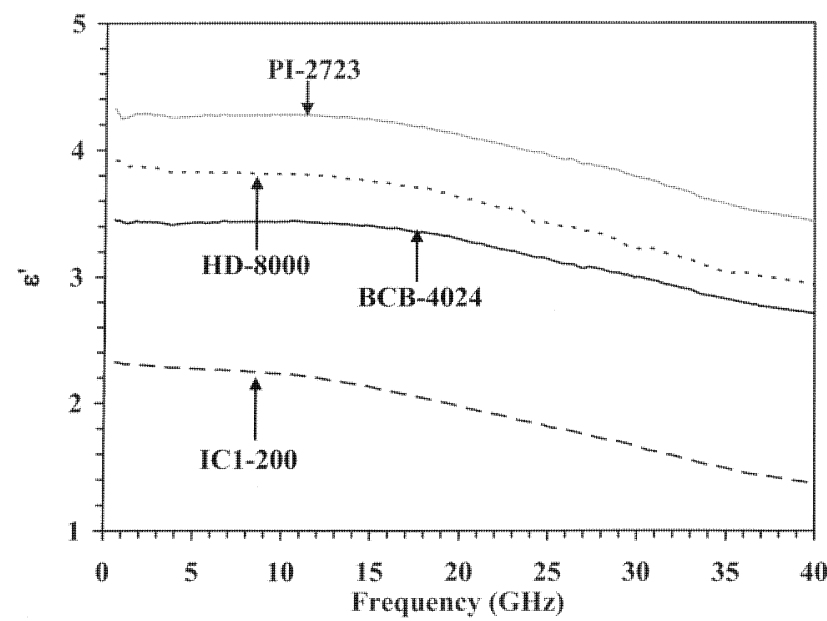

Figure 6. Measured real part of dielectric permittivity vs. frequency.

reflection coefficients by $Z=Z_{0}\left(1+S_{11 \text { meas }}\right) /\left(1-S_{11 \text { meas }}\right)$, where $S_{11 \text { meas }}$ is the measured reflection coefficient and $Z_{o}$ is the vector network analyzer impedance $(50 \Omega)$. The relation between the measured and calculated capacitors' impedances is expressed as [42]

$$
\frac{d}{j \omega \varepsilon_{0}\left(\varepsilon^{\prime}-j \varepsilon^{\prime \prime}\right) A}=Z_{0}\left(\frac{1+S_{11 \text { meas }}}{1-S_{11 \text { meas }}}\right)
$$

Solving equation (1) for the real and imaginary parts of $\varepsilon^{\prime}-j \varepsilon^{\prime \prime}$ results in

$$
\begin{aligned}
& \varepsilon^{\prime}(\omega)=\left(\frac{d}{\omega \varepsilon_{0} A}\right) \frac{1}{Z_{0}} \operatorname{Im}\left(\frac{1-S_{11 \text { meas }}}{1+S_{11 \text { meas }}}\right) \\
& \varepsilon^{\prime \prime}(\omega)=\left(\frac{d}{\omega \varepsilon_{0} A}\right) \frac{1}{Z_{0}} \operatorname{Re}\left(\frac{1-S_{11 \text { meas }}}{1+S_{11 \text { meas }}}\right)
\end{aligned}
$$

Figures 6 and 7 illustrate $\varepsilon^{\prime}(\omega)$ and $\varepsilon^{\prime \prime}(\omega)$ extracted from the measured data using equations (2) and (3) respectively. The tangential loss, $\tan \left|\delta_{d}\right|$, is shown in Figure 8 and was obtained by calculating the ratio $\varepsilon^{\prime \prime}(\omega) / \varepsilon^{\prime}(\omega)$ [41] using results from equations (2) and (3).

The data clearly show the frequency dependence of $\varepsilon^{\prime}, \varepsilon^{\prime \prime}$, and $\tan \left|\delta_{d}\right|$ for the studied dielectrics. The real part of the dielectric permittivity for all studied dielectrics monotonically decreases as frequency increases. The dielectric losses and thus loss tangents initially increase approximately linearly in frequency before reaching a broad peak and then decreasing. Such a response corresponds to the presence of one or more relaxation phenomena [36, 41, 43]. The maximum dielectric loss for HD-8000, PI2723 , BCB-4024 and IC1-200 occurs at frequencies of 30 , 33,32 , and $25 \mathrm{GHz}$, respectively.

The dielectric parameters $\varepsilon^{\prime}, \varepsilon^{\prime \prime}$, and tan $\left|\delta_{d}\right|$ vary in frequency as the different polarization mechanisms dis-

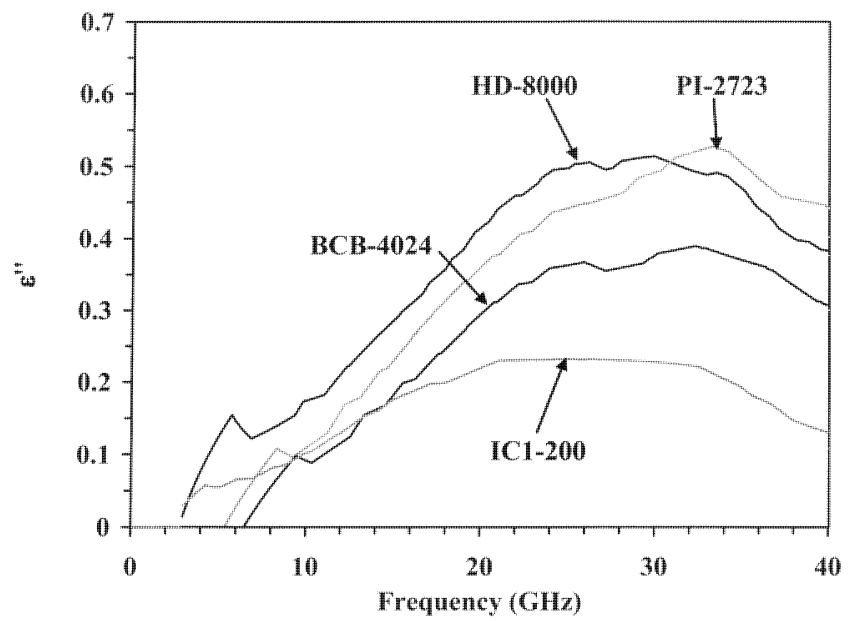

Figure 7. Measured dielectric loss vs. frequency.

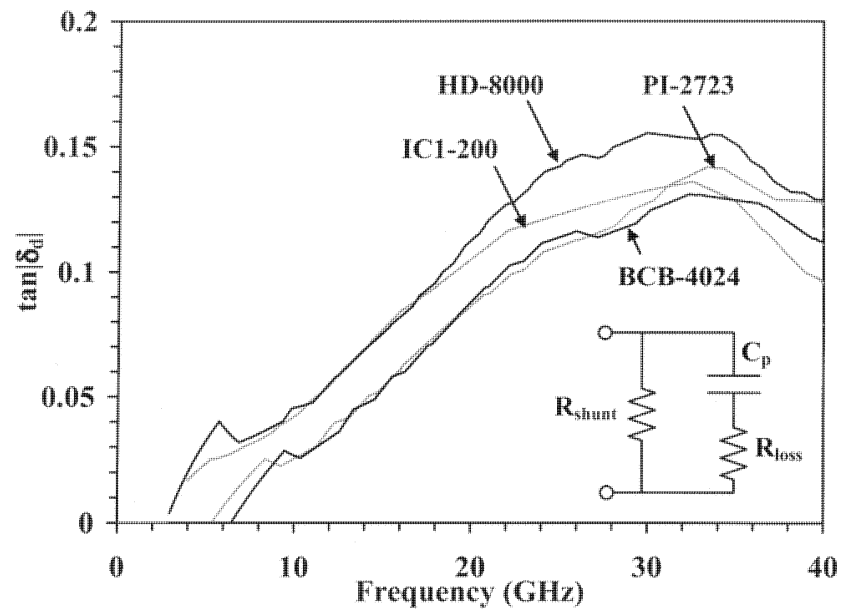

Figure 8. Measured dielectric tangential loss vs. frequency.

cussed in the introduction are selectively excited [18, 19]. As the frequency of the applied field is increased, a point is reached where the permanent electric dipoles (polar molecules) of the material can no longer rotate fast enough to remain in phase with the field. Therefore, contributions of the dipolar polarization mechanism to the net polarization declines, which subsequently causes a reduction in $\varepsilon^{\prime}$, $\varepsilon^{\prime \prime}$, and $\tan \left|\delta_{d}\right|$.

\section{MODELING AND DATA FITTING}

Circuit models are useful for the analysis of high speed bandwidth limitations of electronic devices as well as matching driver circuits to device impedances. A circuit model for the capacitors was developed based on geometrical and physical considerations. The circuit model, shown in the inset of Figure 8, consists of elements corresponding to the physical features of the capacitor, where $C_{p}$ denotes a lossless capacitor between the metal interconnect Ti-Au on top of the dielectric and the bottom plate Ti-Au-Ti. The fringing field at the sides of the top plate 
was neglected since the associated fringing capacitance was estimated to be less than $3 \mathrm{fF}$ [44]. A resistor, $R_{\text {loss }}$, in series with the capacitor models the loss associated with the dielectric dissipation and the shunt resistor, $R_{\text {shunt }}$, represents the resistance of the dielectric material at DC or low frequency due to the leakage current in the capacitor. $R_{\text {shunt }}$ is usually on the order of multi-gigaohms and was assumed to be so large that it has a negligible effect on the model. Numerical calculations assumed a value of $R_{\text {shunt }}=10^{12} \Omega$ to improve convergence. The resistance in the leads and plates of the capacitor is relatively small. The dc plate resistance was estimated to be $\sim 0.15 \Omega$. According to classical theory [45], the ac surface resistance of a conductor is $R_{\mathrm{s}}(\omega)=\left(\mu_{0} \omega / 2 \sigma\right)^{1 / 2}$, where $\sigma$ is the electrical conductivity which equals $4.1 \times 10^{7} \Omega^{-1} \mathrm{~m}^{-1}$ and $2.3 \times 10^{6} \Omega^{-1} \mathrm{~m}^{-1}$ for $\mathrm{Au}$ and Ti respectively, and $\mu_{0}$ is the material permeability that is $4 \pi \times 10^{-7} \mathrm{H} / \mathrm{m}$ for non-ferromagnets. The maximum surface resistance values for $\mathrm{Au}$ and $\mathrm{Ti}$ at $40 \mathrm{GHz}$ were approximately 0.06 and $0.26 \Omega$, respectively. The skin depth is given by $\delta_{s}(\omega)$ $=\left(2 / \omega \sigma \mu_{0}\right)^{1 / 2}$ for a good conductor assuming $\sigma / \omega \varepsilon^{\prime} \gg 1$ [46-49]. At $40 \mathrm{GHz}$, the skin depths of $\mathrm{Au}$ and $\mathrm{Ti}$ were estimated to be $2.1 \mu \mathrm{m}$ and $0.39 \mu \mathrm{m}$ respectively which are larger than the capacitor's plate thickness of $0.33 \mu \mathrm{m}$. Therefore the capacitor plates dc resistance, ac resistance, and skin effect were neglected in the present model and subsequent analysis.

The circuit model impedance can be calculated as

$$
Z_{\text {model }}=R_{\text {loss }}+\frac{1}{j \omega C_{p}}=\frac{d}{j \omega \varepsilon_{0}\left(\varepsilon^{\prime}-j \varepsilon^{\prime \prime}\right) A}
$$

Solving equation (4) for $C_{p}$ results in

$$
C_{p}=\left(1-\frac{\varepsilon^{\prime \prime 2}}{\varepsilon^{\prime 2}}\right) \cdot\left(\frac{\varepsilon_{0} \varepsilon^{\prime} A}{d}\right)
$$

Since $\varepsilon^{\prime \prime 2} / \varepsilon^{\prime 2} \ll 1$, equation (5) can be reduced to $C p=$ $\varepsilon_{0} \varepsilon^{\prime} A / d$ so the frequency dependence of the capacitance

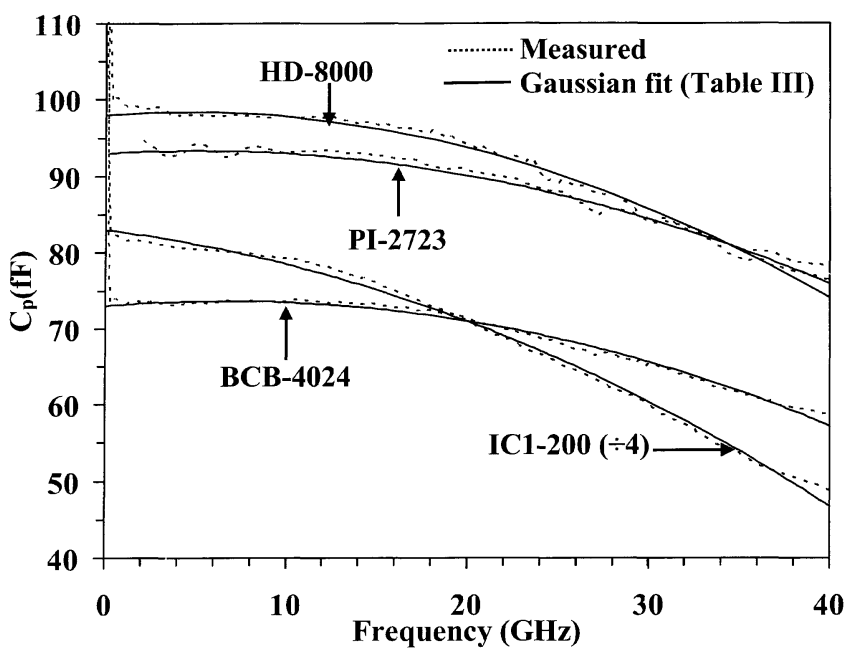

Figure 9. Capacitance vs. frequency. is nearly proportional to the frequency dependence of $\varepsilon^{\prime}$. Solving equation (4) for $R_{\text {loss }}$ results in

$$
R_{\mathrm{loss}}=\frac{\varepsilon^{\prime \prime}}{\varepsilon^{\prime 2}}\left(1-\frac{\varepsilon^{\prime \prime 2}}{\varepsilon^{\prime 2}}\right) \cdot\left(\frac{d}{\omega \varepsilon_{0} A}\right)
$$

which can be approximated as $R_{\text {loss }}=\left(\varepsilon^{\prime \prime} / \varepsilon^{\prime 2}\right)\left(d / \omega \varepsilon_{0} A\right)$ by again neglecting $\varepsilon^{\prime \prime 2} / \varepsilon^{\prime 2}$.

The functional dependence of $\varepsilon^{\prime}$ and $R_{\text {loss }}$ on frequency were found to be well approximated by a Gaussian function with fitting parameters adjusted to minimize the square error to less than $10^{-4}$. Figures 9 and 10 illustrate the extracted and fitted data for $C_{p}$ and $R_{\text {loss }}$ respectively, for the four dielectric materials investigated. The Gaussian functions and coefficients that result in the best fit are listed in Table 3. The values of the real dielectric permittivity at dc $(f=0)$ and very high frequencies $(f \rightarrow$ $\infty)$ were found to be in reasonable agreement with the predicted ones from the Cole-Cole model as discussed in the next section. Furthermore, values of the real dielectric permittivity at $f=0$ were found to be in reasonable agreement with the low-frequency dielectric permittivity values provided by the material vendors and reported by others $[34,50]$ which are also listed in Table 3. As seen in Figure 10 , the extracted values for $\mathrm{R}_{\text {loss }}$ are moderately constant across the frequency range studied, justifying the series resistance model. Average values of $R_{\text {loss }}$ are listed in the table as well, and these constant resistances may suffice in simplified circuit models. The $95 \%$ confidence limits for the values of $\varepsilon_{\mathrm{LF}}, \varepsilon_{\infty}, f_{\mathrm{o}}, R_{\mathrm{LF}}$ and $f_{1}$ are listed in Table 4.

To further investigate the properties of the dielectrics under test, capacitors were fabricated using three different thicknesses of each of the three organic polymers. $S_{11}$ parameters were measured and fitted to the circuit model as discussed earlier for each thickness. Figure 11 illustrates $R_{\text {loss }}$ as a function of the polymer thickness. Results show a linear, approximately proportional dependence on

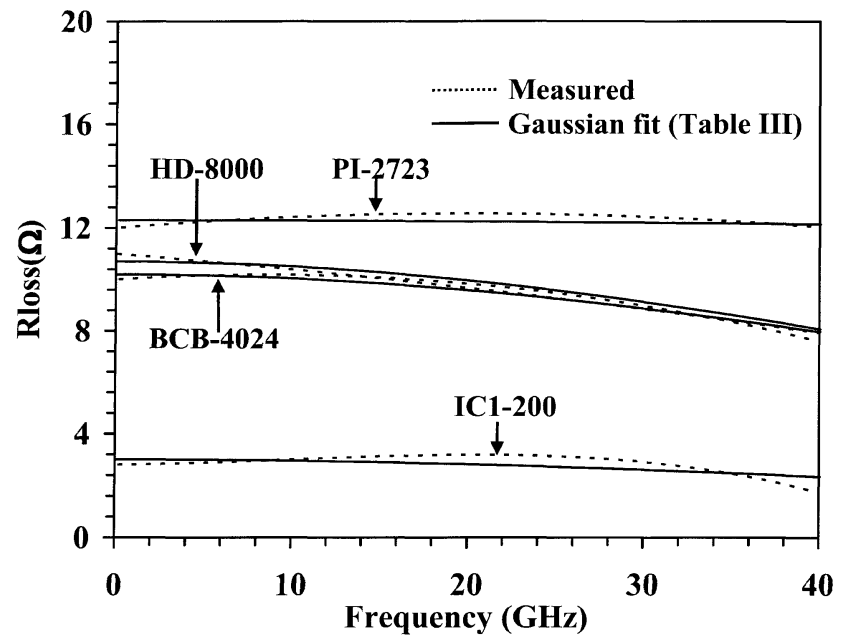

Figure 10. Dielectric loss equivalent resistance vs. frequency. 
Table 3. $\varepsilon^{\prime}(f)$ and $R_{\text {loss }}(f)$ Gaussian functions with their best fitting parameters $\varepsilon_{\mathrm{LF}}, \varepsilon_{\infty}, f_{\mathrm{o}}, R_{L F}$ and $f_{1}$.

\begin{tabular}{|c|c|c|c|c|c|c|c|c|c|c|c|}
\hline \multirow{2}{*}{$\begin{array}{l}\text { Specific } \\
\text { variety }\end{array}$} & \multicolumn{3}{|c|}{$\varepsilon_{L F}$} & \multirow{2}{*}{$\begin{array}{l}\text { Thickness } \\
(\mu \mathrm{m})\end{array}$} & \multicolumn{3}{|c|}{$\varepsilon^{\prime}(f)=\left(\varepsilon_{L F}-\varepsilon_{\infty}\right) \cdot e^{-\left(\frac{f^{2}}{f_{o}^{2}}\right)+\varepsilon_{\infty}}$} & \multirow[b]{2}{*}{$C_{p}(f)$} & \multirow{2}{*}{$\begin{array}{c}\bar{R}_{\text {loss }} \\
(\Omega)\end{array}$} & \multicolumn{2}{|c|}{$R_{\mathrm{loss}}(f)=R_{L F} \cdot e^{-\left(\frac{f^{2}}{f_{1}^{2}}\right)}$} \\
\hline & $\S$ & $\diamond$ & $\ddagger$ & & $\varepsilon_{L F}$ & $\varepsilon_{\infty}$ & $f_{\mathrm{o}}(\mathrm{GHz})$ & & & $R_{L F}$ & $f_{1}$ \\
\hline HD-8000 & 3.4 & 3.9 & - & 3.6 & 3.9 & 2.7 & 103 & & 10 & 10.7 & 75 \\
\hline PI-2723 & 3.3 & 4.3 & - & 4.1 & 4.3 & 3.1 & 120 & $\varepsilon \varepsilon^{\prime}(f) A$ & 11 & 12.3 & 80 \\
\hline BCB-4024 & 3.3 & 3.5 & $2.6^{[50]}$ & 4.3 & 3.5 & 2.4 & 110 & 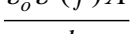 & 11 & 10.2 & 80 \\
\hline IC1-200 & 2.65 & 2.35 & $2.3^{[34]}$ & 0.65 & 2.4 & 1.2 & 70 & $d$ & 2.8 & 3 & 80 \\
\hline
\end{tabular}

\$: vender

$\diamond$ : present work

\$: others

$\varepsilon_{L F}$ : dielectric constant at low frequency.

$f$ : operating frequency $(\mathrm{GHz})$. $\varepsilon_{\infty}$ : extracted from Figure 13

$f_{\mathrm{o}}$ and $f_{1}$ : fitting parameters $(\mathrm{GHz})$.

$C_{p}$ : pad capacitance.

$R_{L F}$ : resistance associated with the dielectric loss at low frequency.

Table 4. $\varepsilon^{\prime}$ and $R_{\text {loss }}$ Gaussian functions best fitting parameters $\varepsilon_{L F}, \varepsilon_{\infty}, f_{0}, R_{L F}, f_{1}$, and $\alpha$, and their $95 \%$ confidence limits.

\begin{tabular}{lllll}
\hline & HD-8000 & PI-2723 & BCB-4024 & IC1-200 \\
\hline$\varepsilon_{\mathrm{LF}}$ & $3.9+0.10 /-0.14$ & $4.3+0.07 /-0.12$ & $3.5 \pm 0.06$ & $2.4+0.06 /-0.05$ \\
$\varepsilon_{\infty}$ & $2.7+0.05 /-0.06$ & $3.1+0.05 /-0.09$ & $2.4+0.03 /-0.04$ & $1.2+0.07 / 0.05$ \\
$f_{\mathrm{o}}(\mathrm{GHz})$ & $103+3 /-13$ & $120+7 /-14$ & $110+7 /-6$ & $70+5 /-4$ \\
$R_{L F}(\Omega)$ & $10.7 \pm 0.4$ & $12.3+0.3 /-0.2$ & $10.2+0.1 /-0.2$ & $3 \pm 0.1$ \\
$f_{1}(\mathrm{GHz})$ & $75+5 /-3$ & $80 \pm 5$ & $80+4 /-2$ & $80+5 /-6$ \\
$\alpha$ & $0.1+0.05 /-0.04$ & $0.11+0.6 /-0.5$ & $0.22+0.04 /-0.1$ & $0.48+0.1 /-0.7$ \\
\hline
\end{tabular}

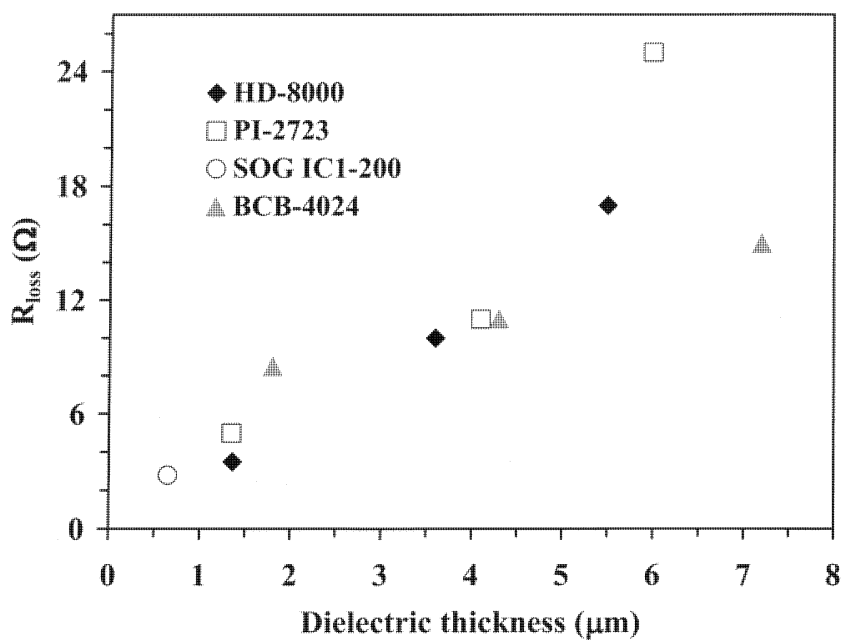

Figure 11. Dielectric loss equivalent resistance vs. dielectric thickness.

thickness as expected from equation (6). Because $R_{\text {loss }}$ is roughly proportional to the dielectric thickness, $d$, while the capacitance is inversely proportional to $d$, the $R C$ time constant of these capacitors is relatively independent of dielectric thickness. In the case of a $50 \Omega$ load shunted by a lossy capacitor driven by a $50 \Omega$ source as shown in the inset of Figure 12 the $3 \mathrm{~dB}$ bandwidth due to the capacitance is neither constant nor proportional to $d$. The actual $3 \mathrm{~dB}$ bandwidth in this case is smaller than what would be expected if the capacitors were lossless for large dielectric thicknesses as illustrated in Figure 12 for HD8000. The other dielectrics have the same trend.

Our previous work [14] modeled the pad capacitor circuit for a VCSEL with a series resistance, $R_{p}$, in order to

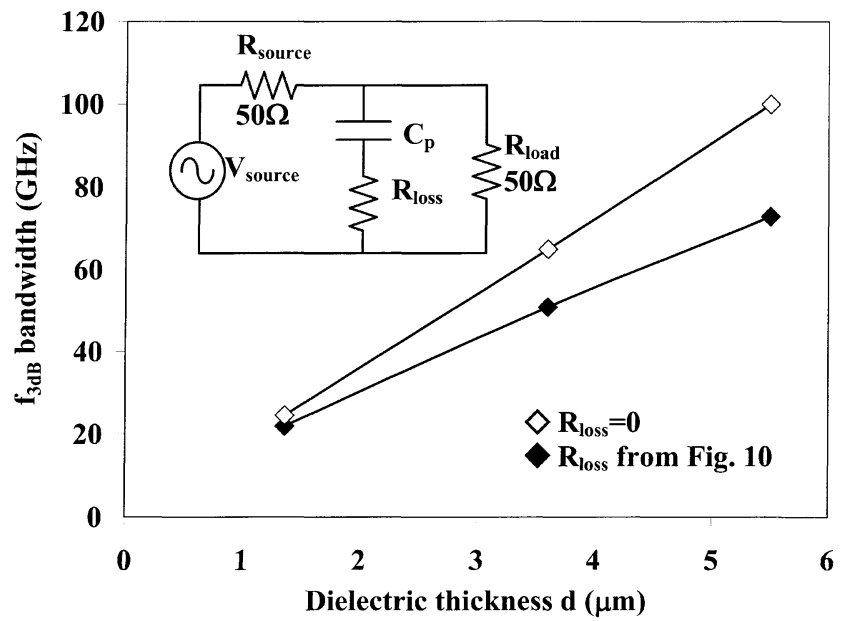

Figure 12. $3 \mathrm{~dB}$ bandwidth vs dielectric thickness.

fit the measured data. In that work, the bottom plate of the parasitic pad capacitor consisted of $p$-type semiconductor mirror stack, and the observed series resistance was attributed to the moderate resistivity of the semiconductor material. The present work indicates that the physical origin of most of this equivalent resistance is in fact dielectric loss.

\section{DEBYE AND COLE-COLE MODELS}

A commonly used model of the complex relative permittivity at microwave and lower frequencies is the Debye model [41, 43] given by

$$
\varepsilon^{*}(f)=\varepsilon_{\infty}+\frac{\varepsilon_{L F}-\varepsilon_{\infty}}{1+\left(j f / f_{\text {peak }}\right)}
$$


where $f$ is the frequency, $f_{\text {peak }}$ is the relaxation frequency at which the dielectric loss peaks, $\varepsilon_{\mathrm{LF}}$ is the dielectric constant at low frequency, and $\varepsilon_{\infty}$ is the dielectric constant at $f \gg f_{\text {peal }}$. A key advantage of the Debye model is that its inverse Fourier transform is an exponential function which permitted the development of numerous computationally effective algorithms to incorporate Debye materials into finite difference time domain simulations (FDTD) [43, 49]. Conversely, the Debye model is often a poor predictor of the dielectric performance of most physical materials since the original Debye treatment for polar molecules assumes that the molecules are spherical in shape and as a result the axis of rotation has no effect on the value of $\varepsilon^{*}(f)$. Furthermore, it neglects the interactions between the molecules in the dielectric material [43] that in practicality are not negligible [51]. Accordingly, the Debye model incorporates only one relaxation frequency $f_{\text {peak }}[49]$.

More accurate models account for molecular interactions [52, 53] and for asymmetric molecular shapes [52]. An example of such an improved model is that of ColeCole [43, 54],

$$
\varepsilon^{*}(f)=\varepsilon_{\infty}+\frac{\varepsilon_{L F}-\varepsilon_{\infty}}{1+\left(j f / f_{\text {peak }}\right)^{1-a}}
$$

where $\alpha$ is an experimental fitting parameter in the range $0 \leq \alpha \leq 1$. The Debye model is a special case of the ColeCole model when $\alpha=0$. It should be noted that the Cole-Cole model's non-integer value of $\alpha$ hinders its inclusion in FDTD computations [49].

To investigate the applicability of the two models mentioned above, approximate values of $\varepsilon_{\infty}$ for all four dielectrics were estimated utilizing the Cole-Cole plot $\left(\varepsilon^{\prime}\right.$ on the $\mathrm{x}$-axis and $\varepsilon^{\prime \prime}$ on the y-axis) by extrapolating the values of $\varepsilon$ to $f \rightarrow \infty$ using equation (8). A best fit for each dielectric material was achieved by allowing the values for $\varepsilon_{\mathrm{LF}}, \varepsilon_{\infty}$, and $\alpha$ to vary. The best fit values and the $95 \%$ confidence limits for $\varepsilon_{\mathrm{LF}}, \varepsilon_{\infty}$, and $\alpha$ are listed in Table 4. By applying values of $\varepsilon_{\mathrm{LF}}$ and $\varepsilon_{\infty}$ in equation (7) plots for the Debye model were also obtained. Figure 13 below illustrates the Cole-Cole plots obtained from experimental measurements, the Debye model, and the Cole-Cole model. The measured curves are very close to a circular arc in conformity with the Cole-Cole model [52, 54].

Based on the plots presented in Figure 13 it is concluded that there are considerable inter-molecular interactions in organic polymers and SOG [53, 54]. Furthermore, the results presented here support the claim in [53] which states that the simple Debye model cannot adequately describe the relaxation process in these materials. However, the Cole-Cole model well describes the experimental data.

Most materials require a finite time for polarization to occur. This time dependence results in a relaxation time $\tau$ that is defined as the time interval characterizing the

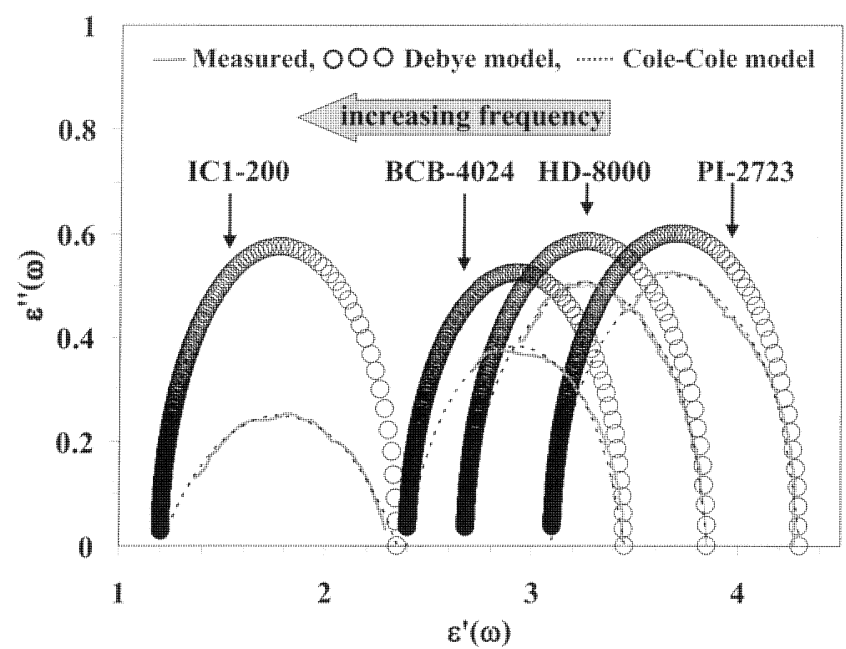

Figure 13. Cole-Cole complex plane plots obtained from experimental measurements, Debye model and Cole-Cole model.

restoration of distributed molecules to their equilibrium state under the effect of an electric field. For dielectrics which cannot be described by the Debye model (one relaxation time), several analytical relations that give a relatively good agreement with the experimental data reported here have been proposed to describe the relaxation time distribution function $G(\tau)[35,36,54,55]$.

\section{CONCLUSIONS}

In this paper, on-wafer, parallel-plate capacitors were fabricated from four different spin-on dielectrics. Multiple dielectric thicknesses were used for the three organic dielectrics. Microwave reflection coefficients, $\mathrm{S}_{11}$, were measured up to $40 \mathrm{GHZ}$ Dielectric permittivities and losses as a function of frequency were extracted from measured microwave reflection coefficients, $\mathrm{S}_{11}$, of the capacitors. The dielectric permittivity is well approximated by a gaussian function, while the dielectric loss and tangential loss peak in the 25 to $34 \mathrm{GHz}$ range. A simple circuit model for the fabricated capacitor was obtained with a minimum square error of less than $10^{-4}$ between measured and modeled reflection coefficients. The behavior of the capacitors over frequency is well approximated by a lossless capacitor with a frequency dependent dielectric permittivity and a constant series resistance. Measurements of different organic polymer dielectric thicknesses confirm that the equivalent series resistance is proportional to the dielectric thickness. The Cole-Cole model, which accounts for molecular shapes and interactions in organic polymers and SOG, provides a good fit to the $\varepsilon^{\prime \prime}$ vs. $\varepsilon^{\prime}$ relationship of the measured data.

For applications to high speed devices, thicker dielectrics result in lower pad capacitance but also higher losses. Accordingly, devices with capacitive pads in $50 \Omega$ environments have $3 \mathrm{~dB}$ bandwidths that increase with increasing dielectric thickness, but not as rapidly as simple 
lossless models would predict. Obtaining models that describe the complex dielectric behavior for high speed devices will improve device simulation and provide more accurate performance predictions. With respect to developing an equivalent circuit model for high speed VCSELs, it is concluded that the doped semiconductor material under the VCSEL pad does not contribute significant loss, but the dielectric provides the majority of the loss in the pad capacitor.

\section{ACKNOWLEDGMENT}

The authors gratefully acknowledge Terry Burcham from Cascade Microtech for fruitful discussions. This work has been supported in part by the Defense Advanced Research Projects Agency under contract number DAAD1903-1-0059 and by Yarmouk University in Irbid, Jordan.

\section{REFERENCES}

[1] A. Kuntman, T. Yilmaz, A. Gungor, and B. M. Baysal, "A New Polyimide Film for VLSI and its Electrical Characterization", IEEE Trans. Dielectr. Electr. Insul., Vol. 5, pp. 296-399, 1998.

[2] D. S. Soone and Z. Martynenko, Polymer in Microelectronics, Fundamentals and Applications, Elsevier, USA, 1989.

[3] N. H. Hendricks, K. S. Y., Lau, A. R. Smith, and W. B. Wan, "Low-permittivity Materials-Synthesis and Applications in Microelectronics", Materials Research Society, San Francisco, California, Vol. 381, p. 59, 1995.

[4] L. B. Rothman, "Properties of Thin Polyimide Films", J. Electrochem. Soc., Solid State Sci. Technol., Vol. 127, pp. 2216-2220, 1980.

[5] H. Gleskova and S. Wagner, "Amorphous Silicon Thin-Film Transistors on Compliant Polyimide Foil Substrates", IEEE Electron Device Lett., Vol. 20, pp. 473-475, 1999.

[6] J. W. Lin, "Use of Polyimide as Interlayer Dielectric for Microelectronic Packing and Passivation Layer for IC Chips", University of California, Berkeley, Short course on Polyimides for Microelectronics Applications, 1981.

[7] N. J. Chou and C. H. Tang, "Interfacial Reaction During Metallization of Cured Polyimide: An XPS Study”, J. Vacuum Sci. Technol., Vol. 2, pp. 751-755, 1984.

[8] K. Morizuka, M. Asaka, N. Iizuka, K. Tsuda, and M. Obara, "AlGaAs/GaAs HBT's Fabricated by a Self-Alignment Technology Using Polyimide for Electrode Separation", IEEE Electron Device Lett., Vol. 9, pp. 598-600, 1988.

[9] C. E. Lindsay, R. F. B. Conlon, R. A. Davies, and A. Hall, "The Effects of Epoxy Die Bonding on the Reliability of Pseudomorphic GaAs/ InGaAs/AlGaAs HEMTs", GaAs Reliability Workshop Proceedings, pp. 87-91, 1998.

[10] A. S. Holmes, R. R. A. Syms, M. Li, and M. Green "Fabrication of Buried Channel Waveguides on Silicon Substrates using Spinon-Glass", Applied Optics, Vol. 32, pp. 4916-4921, 1993.

[11] W. Hafez, Jie-Wei Lai, and Milton, "Reduction of Base-collector Capacitance in InP/InGaAs HBT's Using a Novel Double Polyimide Planarization Process", IEEE Electron Device Lett., Vol. 19, pp. 297-299, 1998.

[12] S. Hyunchol, C. Gaessler, and H. Leier, "Low-Power High-Speed Operation of Submicron InP-InGaAs SHBTs at 1mA", IEEE Electron Device Lett., Vol. 24, pp. 427-429, 2003.

[13] A. Gruhle and P. A. Badoz, "26-GHz Etched-groove Silicon Permeable Base Transistor," IEEE Electron Device Lett., Vol. 12, pp. 556-558, 1991.

[14] A. N. AL-Omari and K. L. Lear, "Polyimide-Planarized, Vertical-Cavity Surface Emitting Lasers with $17.0 \mathrm{GHz}$ Bandwidth", IEEE Photonics Technology Lett., Vol. 16, pp. 969-971, 2004.

[15] Nobuo Aoi, "Novel Porous Films Having Low Dielectric Constants Synthesized by Liquid Phase Silylation of Spin-On Glass
Sol for Intermetal Dielectrics", Japanese J. Appl. Phys., Vol. 36, p. $1355,1997$.

[16] A. C. Madayag and Z. Zhiping, "Optimization of Spin-on-glass process for Multilevel Metal Interconnects", Proc. 14th Biennial University/Government/Industry Microelectronics Symposium, Richmond, Virginia, USA, pp. 136-139, 2001.

[17] Kohei Suzuki, Motoji Yamashita, Nobuyuki Kawakami, Akimitsu Nakaue, "Focused Ion Beam Lithography Using Ladder Silicone Spin-on Glass as a Positive Resist",Japanese J. Appl. Phys., Vol. 35, p. 6517, 1996.

[18] J. Baker-Jarvis, "A Generalized Dielectric Polarization Evaluation Equation”, IEEE Trans. Dielectr. Electr. Insul., Vol. 7, pp. 374-386, 2000.

[19] A. L. S. Loke, Process Integration Issues of Low-Permittivity Dielectrics with Copper for High-Performance Interconnects, Ph.D. Dissertation, Department of Electrical Engineering, Stanford University, Chapter 3, pp. 37-48, 1999.

[20] C. Y. Su, L. P. Chen, S. J. Chang, G. W. Huang, Y. P. Ho, B. M. Tseng, D. C. Lin, H. Y. Lee, J. F. Kuan, Y. M. Deng, C. L. Chen, L. Y. Leu, K. A. Wen and C. Y. Chang, "Effect of Coplanar Probe Pad Design on Noise Figures of $0.35 \mu \mathrm{m}$ MOSFETs", IEE Electronics Lett., Vol. 36, pp. 1280-1281, 2000.

[21] D. K. Walker and D. F. Williams, "Compensation for Geometrical Variations in Coplanner Waveguide Probe-tip Calibration", IEEE Microwave and Guided Wave Letts., Vol. 7, pp. 97-99, 1997.

[22] Ralph Williams, Modern GaAs Processing Methods, Artech House, Boston, London, 1990.

[23] P. B. Chinoy and J. Tajadod, "Processing and Microwave Characterization of Multilevel Interconnects Using Benzocyclobutene Dielectric", IEEE Trans. Components, Hybrids, and Manufacturing Technology, Vol. 16, pp. 714-719, 1993.

[24] A. McKerrow and P. Ho, Proceedings of the Low Dielectric Constant Materials and Interconnects Workshop, SEMATECH 1996, p. 199.

[25] D. Wilson, H. D. Stenzenberger, and P. M. Hergenrother, Polyimides, Chapman and Hall, New York, 1993.

[26] R. L. Kaas, "Autocatalysis and Equilibrium in Polyimide Synthesis", J. Polymer Sci., Vol. 19, pp. 2255-2267, 1981.

[27] D. A. Lewis, J. D. Summer, T. C. Ward, and J. E. McGrath, "Accelerated Imidization Reactions Using Microwave Radiation", J. Polymer Sci.: Part A, Vol. 30, pp. 1647-1653, 1992.

[28] M. E. Clarke, "Introducing Low-k Dielectrics into Semiconductor Processing", Mykrolis Application Note MAL123, pp. 6-7. Available: http://www. mykrolis.com.

[29] T. Shimoto, K. Matsui, and K. Utsumi, "Cu/photosensitive-BCB Thin Film Multilayer Technology for High Performance Multichip Models", IEEE Trans. on Components, Packaging and Manufacturing Technology, Vol. 17, pp.18-22, 1995.

[30] P. E. Garrou, R. H. Heistand, M. G. Dibbs, T. A. Manial, C. E. Mohler, T. M. Stokich, P. H. Townsend, G. M. Adema, M. J. Berry, I. Turlik, "Rapid Thermal Curing of BCB Dielectric", IEEE Trans. on Components, Hybrids, and Manufacturing Technology, Vol. 16, pp. 46-52, 1993.

[31] G. Passemard, et. al., "Single Damascene Integration of BCB with Copper", VMIC Proceedings, p. 63, 1998.

[32] S. Bothra and M. Kellam, "Feasibility of BCB as an Interlevel Dielectric in Integrated Circuits", J. Electronic Materials, Vol. 23, No 8, 1994

[33] N. Hacker, "Organic and Inorganic Spin-on Polymers for Low Dielectric Constant Applications", Materials Research Society Bulletin, October, 1997.

[34] Pei-Lin Pai, arun Chetty, Robert Roat, Neal Cox, and Chiu Ting, "Material Characteristics of Spin-on Glass for Interlayer Dielectric Applications", J. Electrochemical Society: Solid-State Science and Technology, Vol. 134, No. 11, pp. 2829-2834, 1987.

[35] K. Jonscher, Dielectric Relaxation in Solids, Chelsea Dielectric Press, London, UK, 1983.

[36] G. R. Govinda Raju, "Analytical Evaluation of Distribution of Relaxation Time", IEEE Conf. Electr. Insul. Dielectr. Phenomena (CEIDP), pp. 179-182, 2000. 
[37] Agilent Technologies, " 8 Hints for Successful Impedance Measurement", 346-4, pp. 3-7. Available: http://www.agilent.com.

[38] K. E. Jones, E. W. Strid, and K. R. Gleason, "mm-wave wafer probes span 0 to $50 \mathrm{GHz}$ ", Microwave J., Vol. 30, pp. 177-183, 1987.

[39] A. Beroual and C. Brosseau, "Comparison of Dielectric Properties Determined from a Computational Approach and Experiment for Anisotropic and Periodic Heterostructures", IEEE Trans. Dielectr. Electr. Insul., Vol. 8, pp. 921-929, 2001.

[40] D. J. Powell, J. Mould, and G. L. Wojcik, "Dielectric and Mechanical Absorption Mechanisms for Time and Frequency Domain Transducer Modeling", IEEE Ultrasonic Symposium Proceedings, Vol. 2, pp. 1019-1024, 1998.

[41] P. J. Debye, Polar Molecules, the Chemical Catalog Co., New York, NY, 1929.

[42] G. G. Raju, Dielectrics in Electric Fields, Marcel Dekker, Inc., first editing, New York, NY, pp. 97-195, 2003.

[43] D. F. Kelley and R. J. Luebbers, "Debye Function Expansions of Empirical Models of Complex Permittivity for Use in FDTD Solutions", IEEE Antennas and Propagation Society Intern. Sympos., Vol. 4, pp. 372-375, 2003.

[44] W. Liu, Fundamentals of III-V Devices HBTs, MESFETs, and HFETS/HEMTs, John Wiley and Sons, pp. 490-494, 1999.

[45] L. W. Duncan, "Computation of RF Surface Resistance Using the Anomalous Skin Effect Theory", IEEE Trans. Microwave Theory Techn., Vol. 19, pp. 131-132, 1968.

[46] N. S. Nahman and D. R. Holt, "Transient Analysis of Coaxial Cable Using the Skin Effect Approximation A+B $(\mathrm{s})^{0.5}$ ", IEEE Trans. Circuit Theory, Vol. CT-19, pp. 443-451, 1972.

[47] C. T. A. Johnk, Engineering Electromagnetic Fields and Waves, John Wiley and Sons, Inc. pp. 171-174, 1975.

[48] W. D. McCaa, Jr., and N. S. Nahman, "Coaxial-line Pulse-response Error Due to a Planar Skin-effect Approximation", IEEE Trans. on Instruments and Measurements, Vol. IM-21, pp. 515-519, 1972.

[49] D. F. Kelley and R. J. Luebbers, "Piecewise linear recursive convolution for dispersive media using FDTD", IEEE Trans. Antennas Propagation, Vol. 44, pp. 792-797, 1996.

[50] K. R. Carter, "The Road to Low Dielectric Constant Materials", Proceedings from the Ninth Meeting of The Symposium on Polymers for Microelectronics, Wilmington, DE, USA, 2000.

[51] W. H. Abd. Majid and T. H. Richardson, "Dielectric Properties of a Superlattice Containing a Linear Copolysiloxane Substituted with Aromatic Acid Side Chains Langmuir-Boldge", IEEE Intern. Conf. Semiconductor Electronics, pp. 29-33, 2000.

[52] A. Chelkowski, Dielectric Physics, Elsevier Scientific Publication Company, 1980.
[53] K. S. Cole and R. H. Cole, "Dispersion and Absorption in Dielectrics: I. Alternating Current Characteristics", J. Chem. Phys., Vol. 9, pp. 341-351, 1941.

[54] C. Elissalde, J. Ravez, and P. Gaucher, "High Frequency Dielectric Relaxation in $\mathrm{Pb}\left(\mathrm{Mg}_{0.317} \mathrm{Nb}_{0.633} \mathrm{Ti}_{0.05}\right) \mathrm{O}_{3}$ Ceramics", Proceedings 8th IEEE Intern. Sympos. Applications of Ferroelectrics, pp. 458-461, 1992.

[55] A. K. Jonscher, "Dielectric Relaxation in Solids", J. Physics D: Applied Physics, Vol. 32, pp. R57-R70, 1999.

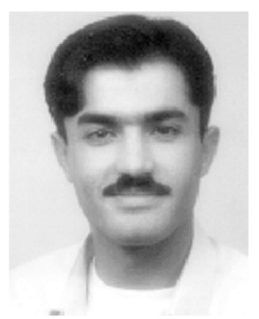

Ahmad N. AL-Omari (SM'03) received the B.S. degree in electronics engineering from Yarmouk University, Irbid, Jordan in 1995 where he was subsequently a research assistant until 2000. He completed his M.S. degree in electrical engineering from Colorado State University, Fort Collins, Colorado, in 2002 where he is currently a Ph.D. student. His research interests include design, fabrication, characterization and modeling of high speed oxide confined vertical-cavity surface-emitting lasers (VCSELs) as well as dielectrics for high speed devices Mr. ALOmari is a Student Member of the International Society for Optical Engineering (SPIE), the Honor Society for Electrical and Computer engineers Eta Kappa Nu (HKN), the Optical Society of America (OSA), and the Institute of Electrical Engineers (IEE).

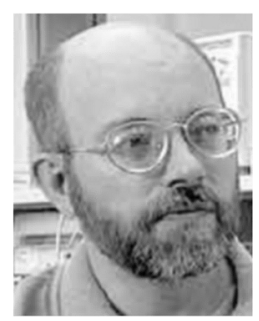

Kevin L. Lear (SM'88-M'90) received the B.S.E.E. degree from the University of Colorado, Boulder, in 1984, and the M.S.E.E. and Ph.D.E.E. degrees from Stanford University in 1985 and 1990, respectively. $\mathrm{He}$ was a Senior Member of Technical Staff at Sandia National Laboratories from 1990 to 1997 where his work on VCSELs led to several performance records and recognition with an IEEE LEOS Distinguished Lecturer Award in 1996. In 1997, he became the Chief Scientific Officer at Micro Optical Devices, Inc., of Albuquerque, NM, a small business commercializing VCSELs, subsequently acquired by Emcore Corporation. In 1999 he joined Colorado State University as the Rockwell Anderson Associate Professor of Electrical and Computer Engineering. His research is currently focused on components and systems for high speed optical communication and photonic biosensors. 